\title{
Research on the influence of cultural diversity in the global integration
}

\author{
Guo Xian
}

Xi'an International University, Xi'an, 710077, China.

Keywords: culture; integration; diversification

\begin{abstract}
Cultural diversity is a kind of new thinking, in different times, cultural core, the deep structure of culture will face different challenges and make positive response to the challenge, but all this should be based on the characteristics of the national culture, global impact is enormous. In many aspects, including economic organizations as the traditional location of the nation-state in the faded; it brings many new, constructive, potentially influential social organizations as well as new groups; new technology, new changes in the mode of production and consumption of these nineteenth Century industrialization, human production Have a completely different from the past, the new sensibility, there is a new way of life in the world. At the same time, discusses the role of cultural diversity in European integration, shaping the ideological and cultural foundation of EU in the common cultural base, which has become an important guarantee for deepening of European integration.
\end{abstract}

\section{The meaning of "cultural diversity"}

Cultural diversity is the meaning of multi-level. It is not only in the global scope of the coexistence of different ethnic and cultural prosperity, but it also means that in a single nation in the traditional culture of other ethnic culture tolerance and necessary absorption, the most important is that cultural diversity is a kind of new thinking. It requires people from a traditional way of thinking to change the type of multi type thinking method, from theory to absolute relativity.

Deep structure culture is the core of those in the global range of different ethnic culture to different cultural fundamental qualities, this is what Benedict said in the $<>$ in the mode of culture: "culture is a kind of thinking and behavior patterns through a national activity shown by a the different nationalities in other national mode. If it is the fundamental problem to treat the cultural from this aspect of the case, such as food culture, clothing culture, living culture, nature will be excluded from the cultural core. The cultural core of what we say here, the deep structure of culture of each nation is flowing in the heart, show It is not only a kind of thinking and behavior pattern, but also includes the national belief and the value tendency, but the language, art, religion, philosophy and so on are its main objective carrier.

As the core of the deep structure of culture is different from that in the political and economic basis, the concept of the superstructure culture. This culture concept, its essence is a kind of ideology, and it must adapt to the political, economic development, and the resulting and generation of cultural forms, such as the feudal culture, capitalism culture, socialist culture. In our opinion, these cultural patterns is the cultural structure of the surface, but in this behind, also hidden deeper things, they are in the era of feudalism culture, capitalist culture and socialist culture.

It is based on the stability of the deep structure of culture, it is in the global scope for cultural diversity provides a possibility. Of course, in different times, cultural core, the deep structure of culture will face different challenges and make positive response to the challenge, but all this should be based on the characteristics of the keep the national culture, on this basis, under the premise of ensuring the continuity of national culture of the core, can without hesitation absorption and integration from heterogeneous culture of the nation's overall cultural development of useful things, so as to realize the diversification of culture in nation states. Or you can go farther away, in. The premise of the national culture card dominant position, the core value of culture, other culture also hold a tolerant attitude in the nation, as long as it does not constitute the national culture the core value of the infringement. And to do all this, obviously depends on a method of diversification. 


\section{The development status and trend of global integration of culture}

On the current situation, "cultural diversity" is a forward-looking vision, or a limited group of intellectuals in talking about the topic, and the "globalization" is a an established fact. Although postcolonial theory, including Saeed's "Eastern" theory, in the criticism of western center the relationship between the East and the West in the process of globalization and on this basis, but its theoretical terms, thinking space, criticism, is still carried out in the context of western culture, is still confined to the western knowledge system. In Saeed, Orientalism is a product of western culture, Western self The projection of subjectivity, the reflection of power, his deconstruction and criticism of the west, is still the western discourse, rather than "the true words of the East".

The impact of globalization is enormous, in many aspects. The American scholar J Hillis Miller in Beijing last year made entitled "on impact of globalization on the research literature on the academic report, talked about the three important influence among them: the first one is" the decline since eighteenth Century as a political and social organization the dominant form of nation-state with integrity and power. The development of new science and technology have made the globalization of business, therefore, as the traditional economic organization where the nation-state in the waning days ";" second impact of globalization is that it brings many new, constructive, have potential influence The social organization and the new group "; the third impact is the impact on people's own, he quoted W Benjamin," new technology, new changes in the mode of production and consumption of these nineteenth Century industrialization, mankind created a completely different from the past, followed by a new sensibility. A new way of life "in the world.

Of course, globalization will first national political power constraints, will achieve the "unlimited government" to "limited government transition". There is also the government transfers out of the direct management of economic power will be more and more international economic organizations to succeed, for example in the Asian financial crisis, the world bank, play the International Monetary Fund's role and influence, can illustrate this point obviously. The influence of globalization on the cultural problems involved, because no matter what kind of culture, is to care for the people as their main duty. With the advent of the information age, communication tools of transportation, new the Entertainment, especially the Internet, changes in the way of life of people will become more and more obvious, the subjective feelings of the people will have more and more influence.

Globalization not only makes people experience mode of variation, but also brought the crisis of identity, the identity crisis occurred in the industrialization, industrial production caused the alienation, and the information produced by the age of loneliness is not a bit less than in the past, even though the increased trend. People can watch TV by telephone, and others to establish more extensive search in the computer on the Internet, more direct contact, but there is no doubt that in this way a connection is with a false, deceptive, people get a lot of speech, auditory, visual reality. Lost, Go to the real experience of self as the emotional and rational unity. The possibility of cultural pluralism and rationality, it is a kind of spiritual loss brought by globalization based on the human and the resulting, it is the reality of global integration in soil.

\section{The promotion of European integration cultural European construction strategy}

Today, the European integration is confronted with the dual task of deepening and expanding. In this case, the construction of culture in Europe will inevitably put on the agenda. The father of Europe, Jean Monet said, if we can do it again, I will start from the aspect of culture. Cultural construction is not only the inevitable choice for Europe to further integration, but also consolidate the economy, a powerful guarantee of political integration. Therefore, the importance of European culture construction has attracted more and more attention from all walks of life in Europe.

A concept in recent years, Europeans talk is more "European culture". They use the term "culture" is complex, so the European culture is not a culture, it is the combination of culture. "The essence of the cultural Europe" is that the EU based on the common culture to realize cultural integration further, in order to promote the development of European integration and the deepening 
of European civilization.

In European history, the formation of cultural diversity. In view of the characteristics of history and reality, the construction of culture in Europe must take a diversity and integration way. Mr. Chen Lemin says the "idea of Europe": the "idea of Europe" reflects "the two meanings of the same interleaving" and "diversity". Therefore, the European cultural construction must choose diversity and integration principle. This is the only viable option.

In recent years, European countries have made great efforts in the aspect of culture. They realize that youth is the hope and future of the European culture. Therefore the cooperation in the fields of education to develop and implement some plans, such as 70 s will promote foreign language teaching and cooperation in higher education on the agenda, and by 80s the "citizens of Europe" to strengthen cooperation in education and training efforts. Emphasize the difference of European cultural diversity and different countries and regions of the European Union on the one hand, on the other hand also proposed to protect European common important cultural heritage. Member countries in promoting cultural prosperity in respect of national and regional diversity. However, in Europe The Union also recognized the difficulty and complexity of the European cultural construction. So it has adopted the "political economy first, basic policy of social culture to keep up. So, about culture, education programs are mostly for capital, personnel flow across national boundaries and developed. And also stressed that the implementation of these plans should be in line with" the auxiliary principle ", namely" bottom-up ", as far as possible by the countries responsible for themselves.

\section{The cultural factors that hinder the development of European Integration}

Admittedly, a long European culture has existed. People in other areas more often than the Europeans themselves more easily recognize it. But after seeing the cultural factors of the development of European integration plays a positive role in promoting at the same time, we should also see the blocking effect of cultural factors on the European integration as Luigi Barzjni said. "What is the hidden power in Western Europe hinder as milk coagulant immediately form a delicious cheese as easily become a solid whole? One thing is very obvious, that is obviously rooted in the existence of the sensitive national pride.". He believes that countries have a taste And to maintain their dignity of the apathy hinders spontaneous European emotion, hindering the rapid realization actual unity. As De Gaulle had complained: how many members there are many kinds of inviolable egoism.

At present, the EU faces eastward in the same culture. If the fifth expansion can be successful, will promote the realization of the European long since the "big Europe" - a dream in the economic, political, diplomatic, military and cultural aspects of a highly unified fusion of the European continent. This kind of words, the ability of the United States leading European affairs and Russian influence in Europe will be greatly reduced. Europe will become a strong political, economic and cultural power pole. On central and East European countries, the European Union is the civilization belonging to "spiritual home", especially the accession round their "return to the European dream", has changed its national property, get rid of The Yalta system imposed by the concept of culture, philosophy and culture, and come back to their hometown. The realization of equality and the Christian culture on Western European countries. This will further strengthen the fight against European American cultural hegemony strategy strength, but the key is how to integrate the EU homologous different streams of national culture, especially in some Eastern European countries is self the system of Slavic culture, also be mixed with the Catholic and Eastern Orthodox churches for thousands of years of disputes, the EU put forward a huge challenge.

The former German Prime Minister Schmidt said: "the Europeans hope. Finally from a national fundamental historical records, and achieve a common European history. It should not be confined to the historic evolution, should also be about a common culture. This will show that although the EU today often said is absolutely a a" legal community ", but it involves a much wider.

Relatively speaking, some ethnic and national common cultural development only a few touch on the mainland. 15 of today's EU countries are playing the majority of European culture brand. 
Today was included in the list of EU candidate countries does not necessarily belong to this category.

We can see that a new round of expansion has brought many problems, the blending of different cultures is more difficult, is not only a new individual has increased the difficulty of construction of common culture, and cultural property does not belong to the Christian civilization in EU countries, put forward the new challenge to the European cultural identity and culture with respect. The social system, such as democracy's standard is difficult to confirm and not easy to change, the formation of its history of inertia seems to be very difficult to change. Different cultural basis of national culture based on its unique way of hindering the deepening of European integration, the reason is that the ethnic culture of ethnic style, European dance Taiwan on behalf of different cultural actors, their behavior is the logical extension of their national cultures, and with the deepening of European integration and EU enlargement, the contradiction of various ethnic cultural differences will be highlighted, and directly influence the cooperation within the EU, and the influence of European integration in the political process, the EU will assume the coordination of national culture friction and the construction of the European cultural task. Some scholars believe that the European countries of Western Europe, in thought, tradition, lifestyle differences and social system of the large, so that "create a closer alliance between the peoples of Europe of the higher level of integration is almost impossible. So they are called For the "European cultural differences pie".

For the EU, political integration means not only the integration of different political culture, also means that the increase in cultural differences between the new political unit. Citizens will influence different attitude towards the integration of integration cost reality and the future, and therefore influence the political integration itself. Only political elite cooperation, no political integration is not public support feasible. Therefore, in the process of European integration today, should make people out of the country, the nation's circle, face a common problem between China and the new insight into the adaptation and integration process, to encourage cooperation cooperation in different cultural groups. If you continue, only Without excessive damage or threat to their respective cultural values, the partners will develop a new common view, guidelines and practices.

\section{The influence of cultural diversity on European Integration}

As can be seen, cultural factors play an increasingly important role in the process of European integration. Shaping the ideological and cultural foundation of EU in the common cultural base, which has become an important guarantee for the deepening of European integration; at the same time also want to see the back of national culture on the common cultural policies do not be anxious for success, only this, European integration can continue deepen.

Europe and nationalism will coexist for a long time, but the general trend is nationalism things will gradually fade. Perhaps, for national things have their cultural characteristics, this characteristic is closely connected with its own history and includes language culture. From the perspective of language, Huntington clearly pointed out: "the two core elements of culture language and religion." on European Christian common belief, but to speak the national language. Since the establishment of European organizations has been a member of the "language equality" in an important position, for example In 2001, the "European language year" in the draft resolution made it clear that: "from the perspective of culture, all European languages have the same value and dignity". In order to achieve this goal, the European Union is the world's largest and most complex translation and interpretation services, but also have special funds for maintenance the EU "linguistic diversity."

At present, the communication within the organization is in eleven languages, with the further enlargement of the EU, it is bound to bring more internal language, while the EU currently has the world's largest translation services. Moreover, the EU's motto "in diversity development" (Strength in diversity) is also guaranteed to Europeans proud of the "polyvocal" in the Bible, it is easy to build Babel, the language is actually? Concept, concept is simple, between the same people exchange will inevitably lead to misunderstanding, and with "I kind of exchange. On this issue, Huntington was "not between different parts of Western civilization could not understand each 
other's things, and with the integration of the role, began to compare the Western civilization and human civilization on the other to discuss the clash of civilizations." therefore, the European cultural identity and diversity will coexist for a long time.

\section{References}

[1] Ji Qiufeng, "The cultural and ideological origins of European integration", "world history", 1998.

[2] Shen Minhua, Cheng Dong, "The European Crusades cultural background", "Social Science ", 2001.

[3] Zhao Boying, "The origin of European unity and historical heritage", "theoretical frontiers", 1999 .

[4] Patricia Weidemer, The Idea Behind Coudenhove-Kalergi's Pan-European Union, History of European Ideas, Pergamon Press, vol.16.

[5] Stavrianos, "Global History: after 1500 the world", Shanghai Social Sciences Press, 1996.

[6] Zhu Ning, "accident Civilization: the end of hegemony and order reconstruction (1000-2000)", Renmin University of China press, 2000.

[7] Li Wei, Wang Xueyu, "the European integration theory and history of literature reading", Shandong people's publishing house, 2001.

[8] Zhou Hong, Chen Lemin, "the process of European civilization ", triple bookstore, 2003. 